\title{
Alterations in milk and blood metabolomes during the first months of lactation in dairy cows
}

\author{
A. Ilves, ${ }^{\star} \dagger^{1}$ H. Harzia, ${ }^{\star} \dagger$ K. Ling, ${ }^{\star}$ M. Ots, ${ }^{\star}$ U. Soomets, $†$ and K. Kilk† \\ ${ }^{*}$ Department of Nutrition and Animal Products Quality, Institute of Veterinary Medicine and Animal Sciences, Estonian University of Life Sciences, \\ 46 Kreutzwaldi St., 51006, Tartu, Estonia \\ †Department of Biochemistry, Medical Faculty, University of Tartu, the Centre of Excellence for Translational Medicine, 19 Ravila St., \\ 50411, Tartu, Estonia
}

\begin{abstract}
The molecular composition of milk is influenced by various genetic and environmental factors. Time is one important factor, and the fact that certain milk components change over the course of lactation is widely accepted. Untargeted global metabolomics is an approach to study hundreds of low molecular weight compounds simultaneously. In this study, mass spectrometry-based global metabolomics was used to follow the course of changes in milk $(\mathrm{n}=133)$ and blood plasma $(\mathrm{n}=133)$ during the early stage of lactation. Little correlation was found between the molecular composition of blood plasma and milk. Blood showed a higher dependence on animal individuality than did milk, in which common evolutions in time resolved. Citrate and lactose had the greatest effect on these changes; however, the most significant changes in milk during the first months of lactation were associated with phosphorylated saccharide levels, whereas the most significant changes in blood plasma were associated with levels of polyunsaturated fatty acids containing phosphatidylcholine. In conclusion, a new systemic approach was used to search for minor metabolites whose concentrations were significantly altered in milk and blood during the first months of lactation.
\end{abstract}

Key words: dairy cow, early lactation, milk and blood metabolome, tandem mass spectroscopy

\section{INTRODUCTION}

Milk is a complex colloidal solution of different macroconstituents synthesized in the mammary gland, and microconstituents originating mostly from blood. It is well known that the concentrations of the main constituents in dairy cow milk differ between breeds

Received April 13, 2012.

Accepted June 12, 2012

${ }^{1}$ Corresponding author: aire.ilves@emu.ee
(DePeters et al., 1995), stages of lactation (Waite et al., 1956), and composition of the ration (Elgersma et al., 2004). It is acknowledged that over the course of lactation, milk composition changes per se, although the most significant changes occur in early and late lactation. During midlactation, the composition of milk remains relatively constant (Fox, 2009).

A greater fat-to-protein ratio (Heuer et al., 2000) and elevation of concentrations of ketone bodies, such as acetone, acetoacetate, and BHBA, in milk are related to the mobilization of body reserves during postpartum energy deficiency (Nielsen et al., 2003). Milk citrate concentration is also higher in early lactation and is related to de novo synthesis of FA (Garnsworthy et al., 2006). Feeding also has an effect on the fat-to-protein ratio (Grant et al., 1990; He and Armentano, 2011) as well as on the urea nitrogen content in milk (Nousiainen et al., 2004).

In blood, energy metabolite profiles, such as NEFA, BHBA, triglyceride, glucose, and insulin, already begin to change by the end of gestation and continue to change during the first weeks of lactation (Holtenius et al., 2003; Bossaert et al., 2008). All these compounds are used to evaluate the metabolic status of a cow.

Metabolomics is the detection of low molecular weight metabolites and their intermediates from biofluids or tissues. It is used widely in many fields, such as pharmacology, toxicology, and diagnostics, and its use and technological development have increased rapidly (Rochfort, 2005; Zhang et al., 2012). So far, however, few data have been available on the milk and blood metabolomes of dairy cows. Boudonck et al. (2009) identified 223 metabolites from 10 different commercially available milk samples, which showed high biochemical variability attributable to the different manufacturing procedures. Klein et al. (2010), who studied the differences in milk metabolites in samples from early, mid, and late lactation, quantified 44 different milk metabolites. Their results confirmed that milk acetone and BHBA levels are positively correlated with the metabolic status of individual cows in early lactation. 
Table 1. Ingredients and chemical composition of the TMR

\begin{tabular}{lc}
\hline Item & Amount $(\mathrm{g} / \mathrm{kg}$ of $\mathrm{DM})$ \\
\hline Ingredient & 280 \\
Grass silage 1 & 104 \\
Grass silage 2 & 292 \\
Barley (crushed) & 180 \\
Rapeseed cake & 124 \\
Corn meal & 10 \\
Mineral mix & 4 \\
Salt & 6 \\
Limestone & \\
Chemical composition & 11.4 \\
ME (MJ) & 160.1 \\
CP & 103.8 \\
MP &
\end{tabular}

${ }^{1}$ Ingredients: calcium, $115 \mathrm{~g} / \mathrm{kg}$; phosphorous, $45 \mathrm{~g} / \mathrm{kg}$; magnesium, $140 \mathrm{~g} / \mathrm{kg}$; sodium, $90 \mathrm{~g} / \mathrm{kg}$.

${ }^{2}$ Calcium, $370 \mathrm{~g} / \mathrm{kg}$.

In addition, higher concentrations of $\alpha$-aminobutyric acid, phosphocholine, and glycine during the first third of lactation were identified. In a more recent study with nuclear magnetic resonance metabolomic analysis, Klein et al. (2012) found that the ratio of glycerophosphocholine to phosphocholine during the first $4 \mathrm{wk}$ of lactation and the high concentration of glycerophosphocholine at midlactation may serve as markers to identify metabolically stable and healthy cows. In addition, no significant correlations between milk and blood plasma metabolites levels were found within the first 5 wk of lactation.

Nuclear magnetic resonance is 1 of the 2 major platforms used in metabolomics. Because of different signal detection principles, nuclear magnetic resonance and mass spectrometry results are not directly comparable. Nuclear magnetic resonance has certain advantages over mass spectrometry, such as noninvasiveness, but at the same time, it suffers from lower sensitivity (Roux et al., 2011). The aim of this study was to investigate low molecular weight metabolites and compare the molecular composition of milk and blood plasma during the first months of lactation with untargeted global metabolomics by using tandem mass spectrometry.

\section{MATERIALS AND METHODS}

\section{Animal Management and Feeding}

Animal use and care was in accordance with the Estonian Animal Protection Act. Cows in a loose housing system at the Estonian University of Life Sciences experimental farm (Eerika Farm LLC, Märja, Estonia) were fed a TMR (Table 1) ad libitum twice a day. The basal diet (60\% concentrates, $40 \%$ silage) consisted of grass silage, barley meal (crushed), rapeseed cake, corn meal, limestone, salt, and a mineral mix for lactating cows. Feed values of the TMR were determined by methods described by the AOAC Int. (2005) and were calculated monthly on the basis of the chemical composition of the ingredients. Cows were milked twice a day, and milk yield was recorded daily. At the beginning of lactation, the mean BW of the 5 clinically healthy multiparous (second- to fifth-parity) Estonian Holstein cows (Table 2) was $642.5 \pm 27.3 \mathrm{~kg}$; their mean ECM yield over the study period $(5.6 \pm 0.5$ to $96.2 \pm 6.6$ DIM) was $43.7 \mathrm{~kg}$ (range of 40.1 to 48.2 ).

\section{Sample Collection}

Milk samples $(\mathrm{n}=133)$ were collected twice a week (October 2009 to April 2010) with in-line milk meters, and samples were stored at $-20^{\circ} \mathrm{C}$ until analyzed for metabolites. Blood samples $(\mathrm{n}=133)$ from the coccygeal vein (Venoject vacuum tubes, Terumo Europe

Table 2. Data on lactation, DMI, ECM, energy balance, and BCS for the cows

\begin{tabular}{|c|c|c|c|c|c|}
\hline \multirow[b]{2}{*}{ Item } & \multicolumn{5}{|c|}{ Cow } \\
\hline & $\mathrm{A}$ & B & $\mathrm{C}$ & $\mathrm{D}$ & $\mathrm{E}$ \\
\hline Lactation & 5 & 3 & 3 & 3 & 2 \\
\hline $\mathrm{DMI}^{1}(\mathrm{~kg} / \mathrm{d})$ & 23.5 & 24.1 & 25.8 & 24.2 & 26.9 \\
\hline $\mathrm{ECM}^{1,2}(\mathrm{~kg} / \mathrm{d})$ & 45.2 & 45.8 & 48.2 & 40.1 & 42.2 \\
\hline Nadir of negative $\mathrm{EB}^{3}$ (DIM) & 11 & 21 & 24 & 10 & 10 \\
\hline Nadir of negative $\mathrm{EB}^{3}(\mathrm{MJ} / \mathrm{d})$ & -207 & -163 & -147 & -161 & -61 \\
\hline Start of positive $\mathrm{EB}^{3}$ (DIM) & 48 & 72 & 56 & 26 & 19 \\
\hline $\mathrm{BCS}^{4}$ before calving & 3.50 & 3.50 & 3.75 & 3.75 & 3.50 \\
\hline $\mathrm{BCS}^{4}$ at end of study period & 2.50 & 2.50 & 2.75 & 2.75 & 2.75 \\
\hline
\end{tabular}


N.V., Leuven, Belgium) were collected after the evening milking on the milk sampling days. Plasma was separated by centrifugation $\left(4,500 \times g, 15 \mathrm{~min}, 22^{\circ} \mathrm{C}\right)$ immediately after sampling and kept at $-20^{\circ} \mathrm{C}$ until analyzed.

\section{Mass Spectrometry Analyses}

The milk samples for mass spectrometry analyses were prepared and analyzed, as described by Harzia et al. (2012), with a hybrid triple quadrupole/linear ion trap tandem mass spectrometry system $(3,200 \mathrm{Q}$ TRAP; AB Sciex Instruments, Foster City, CA). Positive and negative ions (50 to 1,700 Da) were measured with a TurboIonSpray ion source (AB Sciex Instruments, Foster City, CA) using an enhanced mass scan. For compound identification, C18 (Luna 3- $\mu \mathrm{m} \mathrm{C18}$ $100 \mathrm{~A}, 100 \times 2.00 \mathrm{~mm}$; Phenomenex, Torrance, CA) and HILIC (Luna $5-\mu \mathrm{m}$ HILIC 200A, $150 \times 3.00 \mathrm{~mm}$; Phenomenex) columns were used. The system was controlled by Analyst software version 1.4.2 (Applied Biosystems Inc., Foster City, CA).

\section{Statistical Analyses}

To find patterns in the data with a high dimension, principal components analysis (PCA) was used with R-Statistics software version 2.8.1. (BioConductor algorithms; R Development Core Team, 2008). Analysis of variance and the Tukey test were performed to test for significant differences between mean mass-to-charge ratio values. A volcano plot, a scatter plot analysis, was plotted to visualize the change in mean signal intensity versus the statistical significance of the change.

\section{RESULTS AND DISCUSSION}

Principal components analysis is a method to compress data in large matrixes and classify samples based on variations between them. Therefore, PCA was used for preliminary comparison of the mass spectra of milk and blood plasma samples. For each cow, an "evolution" (i.e., directed movement in the plot of principal components) was observed in the milk metabolic profile of negatively charged ions during lactation (Figure 1). Depending on the animal, samples up to 21 to 30

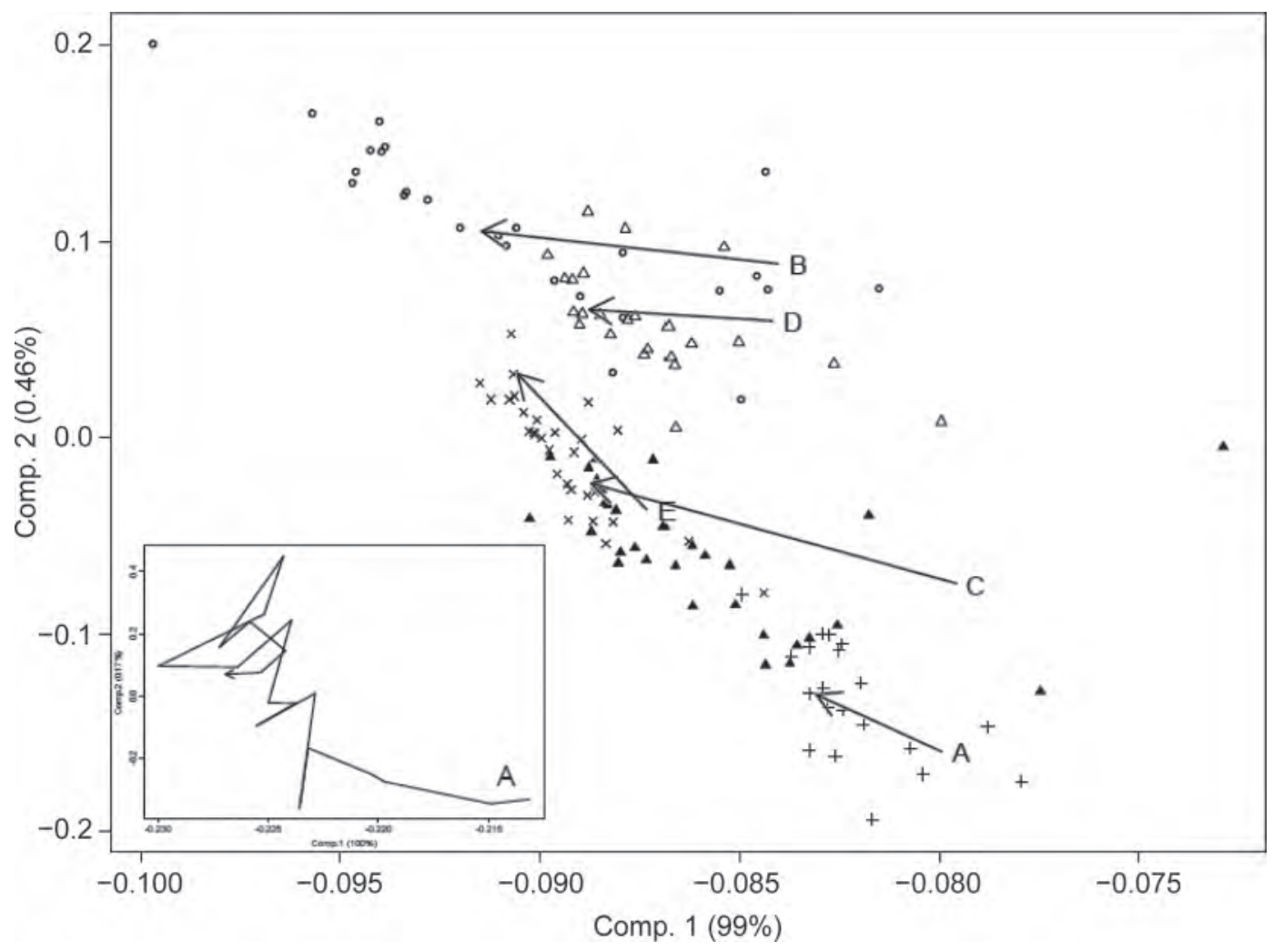

Figure 1. Principal components analysis of milk metabolomes. Each dot represents an entire spectra of negatively charged ions within mass-to-charge ratio $(\mathrm{m} / \mathrm{z}) 50$ to 1,500. The arrow begins from the mean coordinates of the first 5 samples (5 to 20 DIM) and ends at the mean coordinates of the last 5 samples (58 to 74 DIM). Letters A to E indicate individual animals. The inset shows the path from each time point to the next time point for animal A. Comp. = component. 


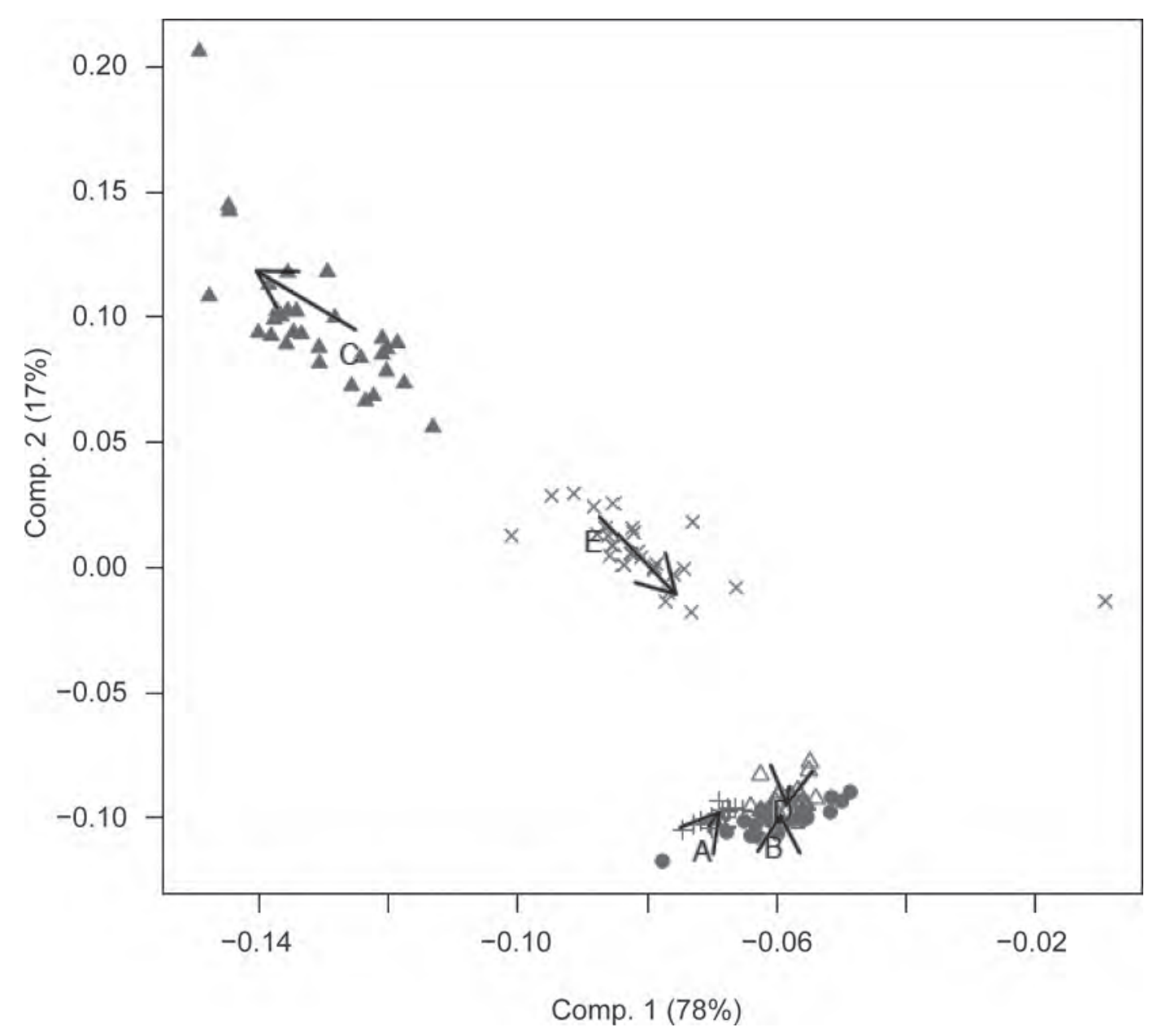

Figure 2. Principal components analysis of blood plasma metabolomes. Each dot represents an entire spectra of negatively charged ions within mass-to-charge ratio $(\mathrm{m} / z) 50$ to 1,500 . The arrow begins from the mean coordinates of the first 5 samples (5 to 20 DIM) and ends at the mean coordinates of the last 5 samples (58 to 74 DIM). Letters A to E indicate individual animals. Comp. = component.

DIM were those classified by PCA as determining the evolution and were separated from the samples from subsequent DIM. Global metabolite spectra from samples beyond the first lactation month showed lower variability, implying less significant changes after that time point. The differences between the individual animals make their direct comparison and averaging of the results difficult. Figure 1 shows that, despite the different starting and end points, the direction of evolution from the first to the second month of lactation is common. This implies that the milk metabolites behind the shift are the same in all cases. Loading plots suggested signals with $m / z 117,119,121,161,163$ (all identified as saccharides or fragments thereof), 191 (citrate), 341 (lactose), and 377 (unknown) as the main contributors to the 2 highest principal components. On the basis of fragmentation spectra, the saccharides contained no phosphate or sulfate groups. In positive ionization mode spectra, the highest variance showed no common evolution, yet lower spectra (components 4 and 5, associated with saccharides) did. Therefore, the concentration of preferably positively charged low molecular weight metabolites depended on other factors more than on the lactation stage. Exclusion of the first month time points from the analysis removed the universal direction of evolution, implying that from the second month of lactation, changes in milk composition were minor or individual traits, or both.

The PCA of blood plasma metabolic profiles in the negative mode showed no universal evolution; the patterns of individual animals (A to $\mathrm{E}$ ) were different (Figure 2), and samples from 2 animals (C and E) were classified separately from the other 3. Principal components analysis loading plots, ANOVA, and the Tukey test were used to find mass-to-charge ratio values characteristic for each animal (Table 3). Animals A, B, and $\mathrm{D}$ had 28,15 , and 26 signals, respectively, with a $P$ value of $<0.0001$, which is the estimated metabolome- 
Table 3. Animal (A-E)-specific markers in blood plasma ${ }^{1}$

\begin{tabular}{|c|c|c|c|c|c|c|c|c|c|c|}
\hline Item & \multicolumn{2}{|c|}{$\mathrm{A}$} & \multicolumn{2}{|c|}{ B } & \multicolumn{2}{|c|}{$\mathrm{C}$} & \multicolumn{2}{|c|}{$\mathrm{D}$} & \multicolumn{2}{|c|}{$\mathrm{E}$} \\
\hline \multicolumn{11}{|c|}{ Negative ions } \\
\hline & 161 & $7.9 \mathrm{E}-10$ & 179 & $6.9 \mathrm{E}-09$ & 62 & $2.0 \mathrm{E}-14$ & 266 & $3.1 \mathrm{E}-14$ & 60 & $2.2 \mathrm{E}-14$ \\
\hline & 163 & 3.7E-09 & 234 & $1.4 \mathrm{E}-08$ & 128 & $2.0 \mathrm{E}-14$ & 115 & 8.7E-13 & 179 & $2.3 \mathrm{E}-14$ \\
\hline & 165 & $5.9 \mathrm{E}-09$ & 178 & $4.8 \mathrm{E}-08$ & 194 & $2.0 \mathrm{E}-14$ & 535 & 7.0E-08 & 95 & $2.5 \mathrm{E}-14$ \\
\hline & 137 & $1.6 \mathrm{E}-07$ & 215 & $1.0 \mathrm{E}-06$ & 200 & $2.0 \mathrm{E}-14$ & 478 & $3.2 \mathrm{E}-06$ & 712 & $2.5 \mathrm{E}-14$ \\
\hline & 315 & $3.3 \mathrm{E}-07$ & 733 & $1.3 \mathrm{E}-05$ & 202 & $2.0 \mathrm{E}-14$ & 594 & $4.5 \mathrm{E}-06$ & 675 & $2.6 \mathrm{E}-14$ \\
\hline & 313 & $7.1 \mathrm{E}-07$ & 216 & $4.7 \mathrm{E}-05$ & 206 & $2.0 \mathrm{E}-14$ & 299 & $5.4 \mathrm{E}-06$ & 681 & $2.6 \mathrm{E}-14$ \\
\hline \multicolumn{11}{|c|}{ Positive ions } \\
\hline & $\begin{array}{l}151 \\
478\end{array}$ & $\begin{array}{l}5.6 \mathrm{E}-06 \\
7.7 \mathrm{E}-05\end{array}$ & $\begin{array}{l}503 \\
157\end{array}$ & $\begin{array}{l}1.4 \mathrm{E}-0 \\
3.4 \mathrm{E}-06\end{array}$ & $\begin{array}{l}100 \\
119\end{array}$ & $\begin{array}{l}2.0 \mathrm{E}-14 \\
2.0 \mathrm{E}-14\end{array}$ & $\begin{array}{l}171 \\
157\end{array}$ & $\begin{array}{l}2.4 \mathrm{E}-08 \\
7.9 \mathrm{E}-07\end{array}$ & $\begin{array}{l}502 \\
478\end{array}$ & $\begin{array}{l}1.4 \mathrm{E}-10 \\
3.5 \mathrm{E}-10\end{array}$ \\
\hline & 199 & $5.3 \mathrm{E}-03$ & 508 & $9.7 \mathrm{E}-03$ & 207 & $2.0 \mathrm{E}-14$ & 172 & 3.7E-02 & 95 & $3.6 \mathrm{E}-08$ \\
\hline & 257 & $7.1 \mathrm{E}-03$ & 224 & $1.1 \mathrm{E}-02$ & 225 & $2.0 \mathrm{E}-14$ & 504 & $4.5 \mathrm{E}-02$ & 1,380 & 4.2E-08 \\
\hline & 120 & $8.1 \mathrm{E}-03$ & 260 & $1.6 \mathrm{E}-02$ & 226 & $2.0 \mathrm{E}-14$ & 478 & $5.4 \mathrm{E}-02$ & 1,399 & $5.8 \mathrm{E}-08$ \\
\hline
\end{tabular}

${ }^{1}$ Mass-to-charge ratios $(\mathrm{m} / \mathrm{z})$ for the 10 most significant signals for negatively and positively charged ions are listed. Molecular species behind these signals were not identified (for comments see text).

A)

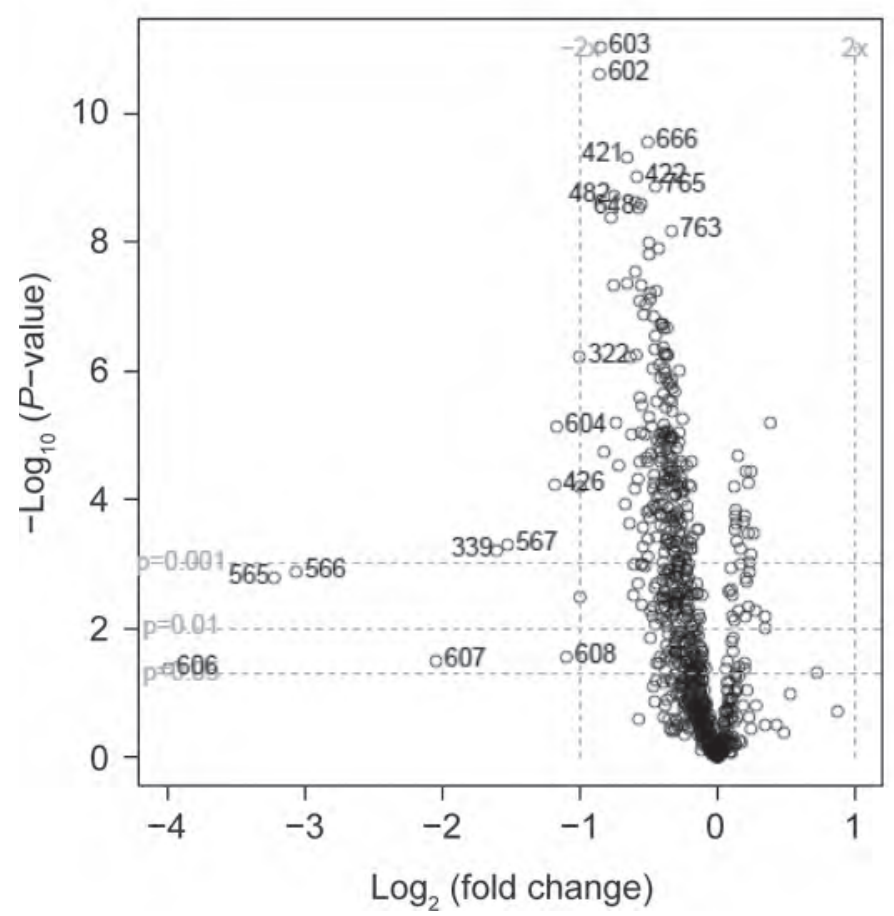

B)

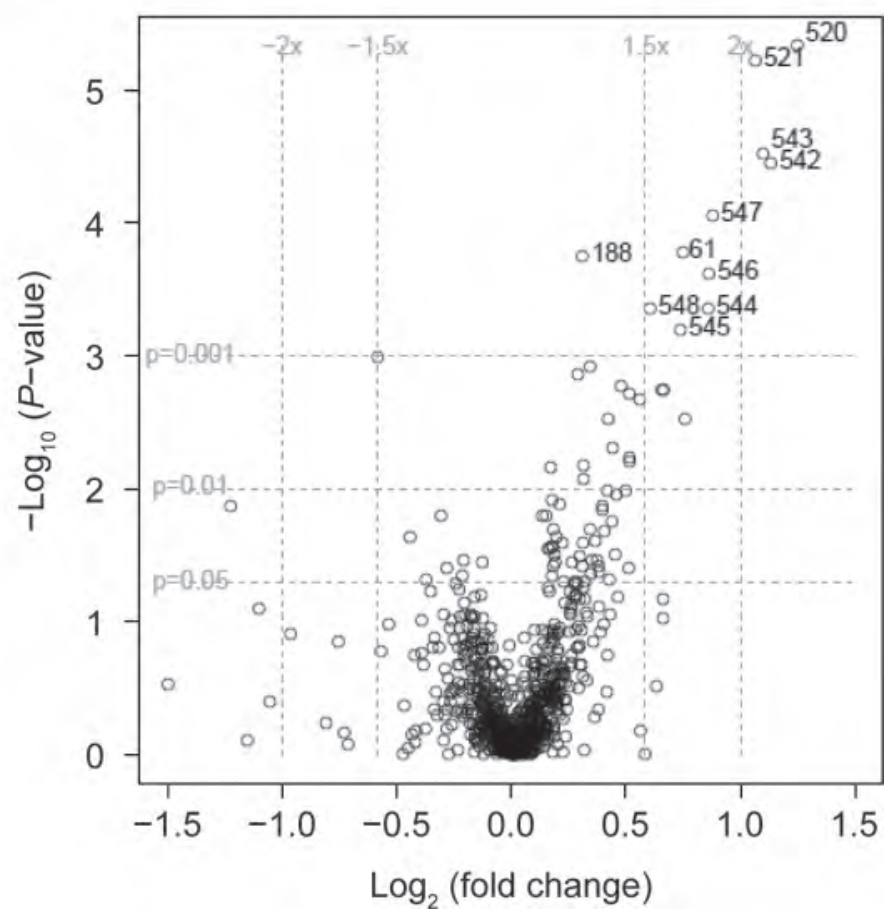

Figure 3. Volcano plots displaying the fold change in mass-to-charge ratio intensity (x-axis) versus the significance of the change (y-axis). Signals with the highest and most significant increase in the first 2 mo of lactation are in the upper right corner. Signals with the highest and most significant decrease in time are in the upper left corner of each figure. A) Negatively charged ions from milk; B) positively charged ions from plasma. Among the positive ions from milk and the negative ions from plasma, no significant changes were observed, so these graphs are omitted. 
wide significance level for the current setup (ChadeauHyam et al., 2010). Animal C had 806 and animal E had 752 signals. However, the enormous number of altered metabolites may be a matrix-related effect, such as ion suppression. High-abundance compounds in a complex mixture may interfere with ionization of other compounds, suppressing detected signal intensities. A major contributor in differentiating animals $\mathrm{A}, \mathrm{B}$, and D from $\mathrm{C}$ and $\mathrm{E}$ was a group of structurally related hydrophilic compounds with $m / z 161,163,196,198$, 200 , and 202. On the basis of intensity, the compounds represented by these signals had high concentrations in plasma and might lead to a background shift in mass spectra and false positive changes in the intensities of unrelated signals. In a comparison of animals A, B, and $\mathrm{D}$, in which the matrix effects were not as striking, animal A had an increase in a group of related signals with $m / z 137,312,313,315$, and 384 . These metabolites were found to be very hydrophobic and could be monoglycerides or FA esters with glycine. Signals $m / z$ 265, 266, and 115 in animal $\mathrm{D}$ were found to have no correlations with other signals; that is, the activities of related metabolic pathways were not significantly affected by the concentration of these compounds, or they were xenobiotics with no related pathways.

The next question was how large and significant the changes were in time. Therefore, volcano plots were created visualizing the change in mean signal intensity versus the statistical significance of the change. Pooling data from all animals showed that the most significantly changed mass-to-charge ratio values in milk were $m / z 601$ to 603,421 to $422,666,482$, and

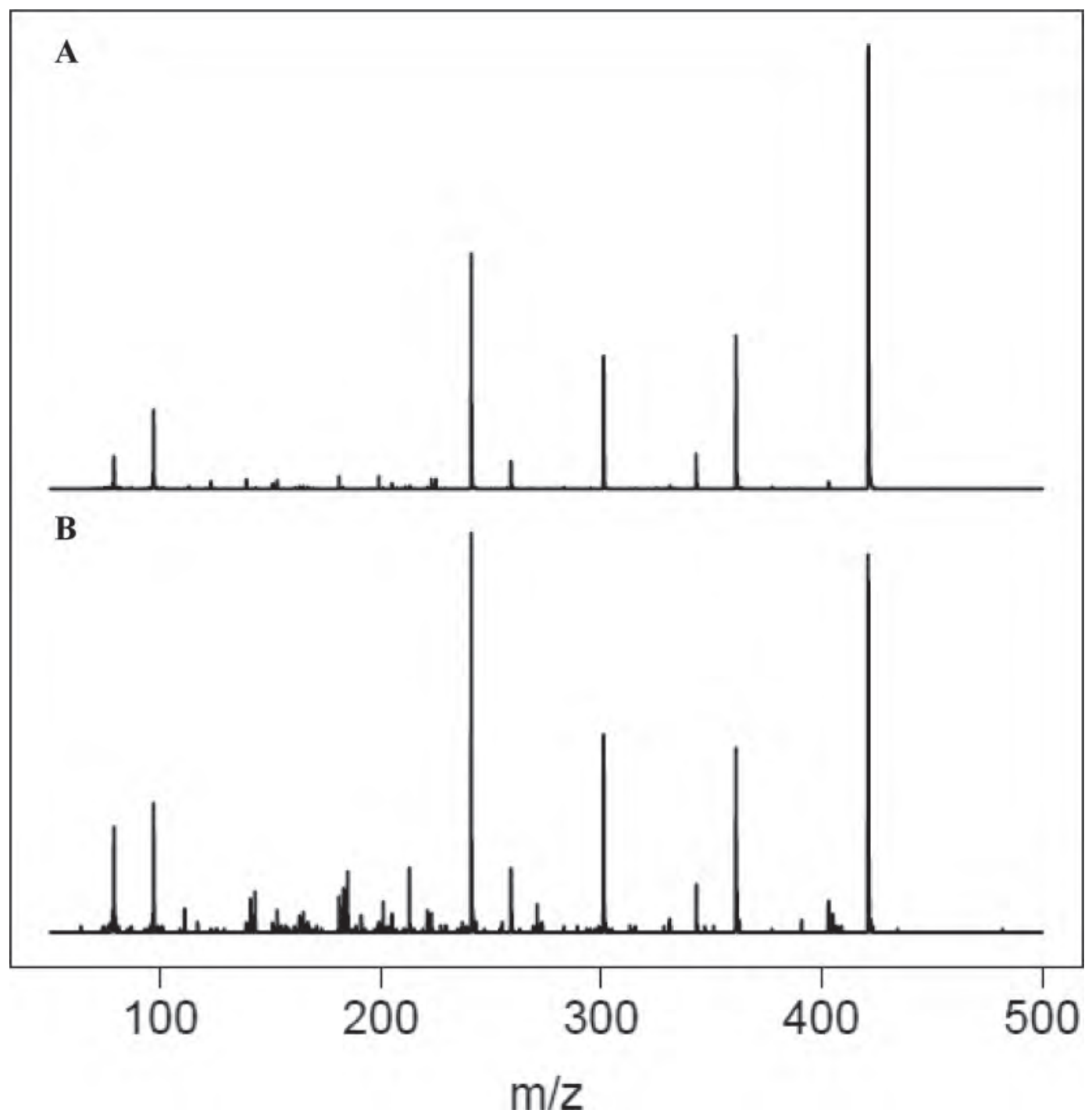

Figure 4. Fragmentation spectra of mass-to-charge ratio $(\mathrm{m} / \mathrm{z}) 421$ from a solution of commercial lactose phosphate (A) and from milk samples (B). 
A)

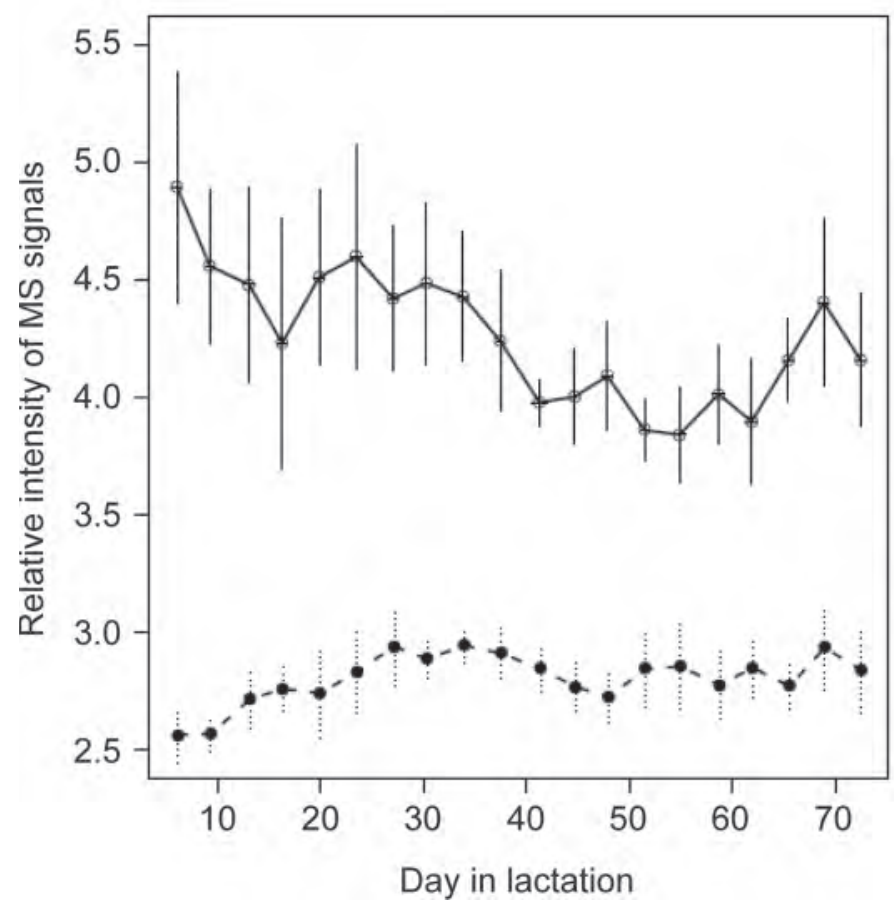

B)

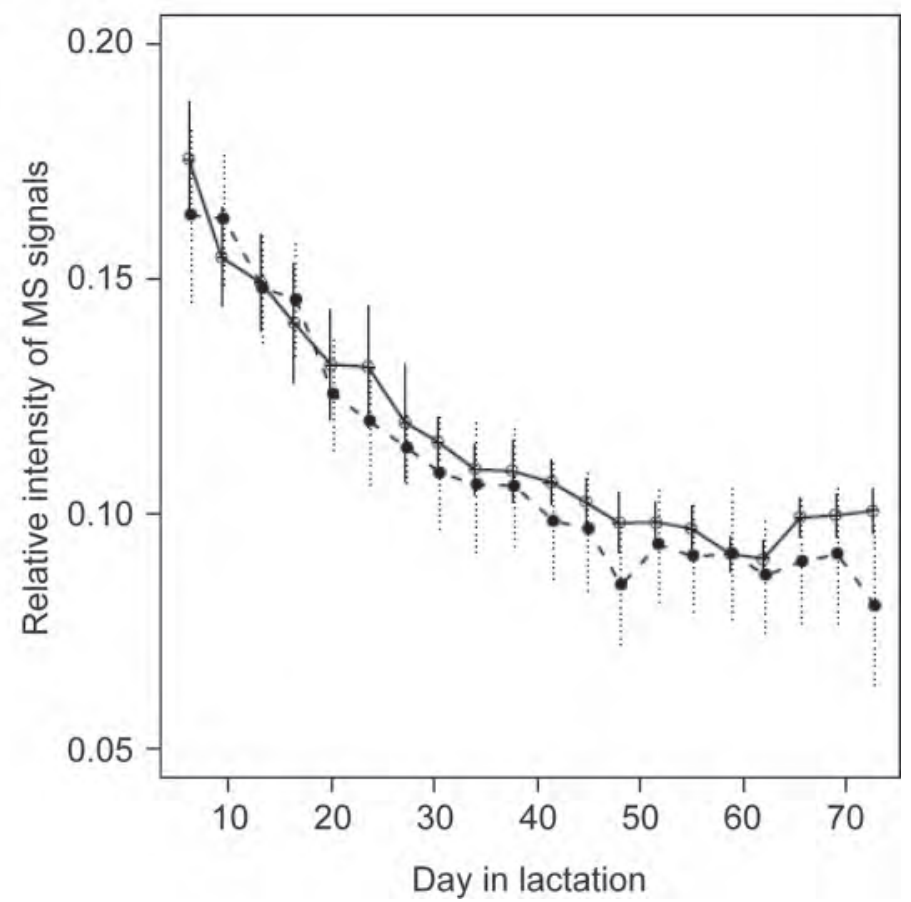

Figure 5. Change in relative signal intensity in milk over the first months of lactation. A) Citrate (solid line), lactose (dashed line); B) lactose phosphate (solid line), mass-to-charge ratio $(\mathrm{m} / z) 601$, unknown phosphosaccharide (dashed line). MS = mass spectrometry.

763 to 765 (negative ions, $P<10^{-8}$; Figure $3 \mathrm{~A}$ ). All these signals decreased by the start of the third lactation month to 75 to $60 \%$ of their initial values. Signals $\mathrm{m} / z 565$ to 566 and 606 to 607 were found to have a more pronounced decrease in time, but with lower significance. Fragmentation analysis revealed a high similarity of $m / z 421$ with lactose phosphate (Figure 4). Signals $m / z 601$ to 603 and 763 to 765 gave only 2 detectable fragments. Both matched signals in the $m / z 421$ spectra. The difference of 162 amu between $m / z 763$ and 601 suggests an additional hexose in 763 compared with 601 . The signal 601 itself is $180 \mathrm{amu}$ more than 421, suggesting a noncovalent complex with additional hexose or a covalent hexose + water. Although the structures of saccharides are difficult to determine by mass spectrometry, these data imply that the substances most significantly decreasing during the first one-third of lactation are phosphorylated saccharides. In an early study, McGeown and Malpress (1952) detected phosphate esters of galactose and lactose in skim milk, with the lactose phosphate concentration being less than $0.1 \mathrm{mg} / \mathrm{L}$. In a later study, Petzold et al. (2004) identified 2 disaccharides with $m / z 421$ in bovine colostrum: a phosphorylated dihexose, Hex2P, with $m / z$ 421.0656, and a sulfated dihexose, Hex2S, with $m / z$ 421.0756. As in the current study, Petzold et al. (2004) found phosphorylated disaccharides in higher abundance. However, taking into account the results of Petzold et al. (2004), it is not possible to exclude the possibility of the involvement of sulfated disaccharides in signal $m / z 421$ in the current study.

According to PCA, citrate and unphosphorylated saccharides (lactose) contributed the most to the milk metabolome evolution during early lactation (Figure 5). Considering the role of citrate in providing reducing equivalents for de novo synthesis of FA in the mammary gland (Garnsworthy et al., 2006), the decrease in its concentration in milk together with advancing lactation is expected. Although the lactose concentration is known to stay relatively constant, changes nevertheless occur during the lactation: an increase at the beginning of lactation and a reduction in late lactation (Rook and Campling, 1965; Muir, 2002). However, citrate and lactose concentrations appear to have high biological variability between animals, making the change statistically less significant than the change in phosphorylated saccharides (Figure 5). Noteworthy is the low variability in the case of phosphosaccharides. For a parallel study, body energy balance was tracked in the same animals. Their period of negative energy balance varied from 19 to 72 DIM, with nadirs from -61 to -207 MJ on DIM 10 to 24 (Table 2). Therefore, 
the hypothesis that energy balance could be the main driver of the decrease in phosphorylated saccharides in milk is unlikely.

As expected from the PCA results and high interindividual differences, changes in blood over 2 mo were less significant than those in milk. Signals $m / z 520$ to 521, 542 to 548, 61 (positive ions; Figure 3B), and 282 (negative ion) were those with at least a $50 \%$ increase, with $P<0.001$. The positively charged ions at $\mathrm{m} / \mathrm{z}$ 520 to 521 and 542 to 548 had fragments characteristic of phosphatidylcholines. From the molecular mass, the most probable FA residues in these lipids are linoleic acid and 20-carbon long-chain FA with 2 to 5 double bonds. Figure 6 presents the fragmentation spectra of $m / z 522$, which was strongly correlated with the listed signals and displayed fragmentation similar to the 2-oleoyl-3- phosphatidylcholine standard. A decrease in the PUFA concentration in milk during lactation has been reported before (Bitman and Wood, 1990; Garnsworthy et al., 2006; Gross et al., 2011). In blood, the reported changes have been similar to those in the current results. Increases have been observed in linoleic acid, the major FA in plasma lipids, within 30 or 60 DIM in the plasma lipid (Douglas et al., 2007; Contreras et al., 2010) and phospholipid fraction (Contreras et al., 2010). For arachidonic acid, stable values (Contreras et al., 2010) or a steady increase within 60 DIM in plasma lipids have been reported (Douglas et al., 2007). A postpartum decrease in plasma phospholipids after a steady increase up to 4 (van den Top et al., 1995) or 7 wk (Guretzky et al., 2006) postpartum has also been observed. Because blood phosphatidylcholine

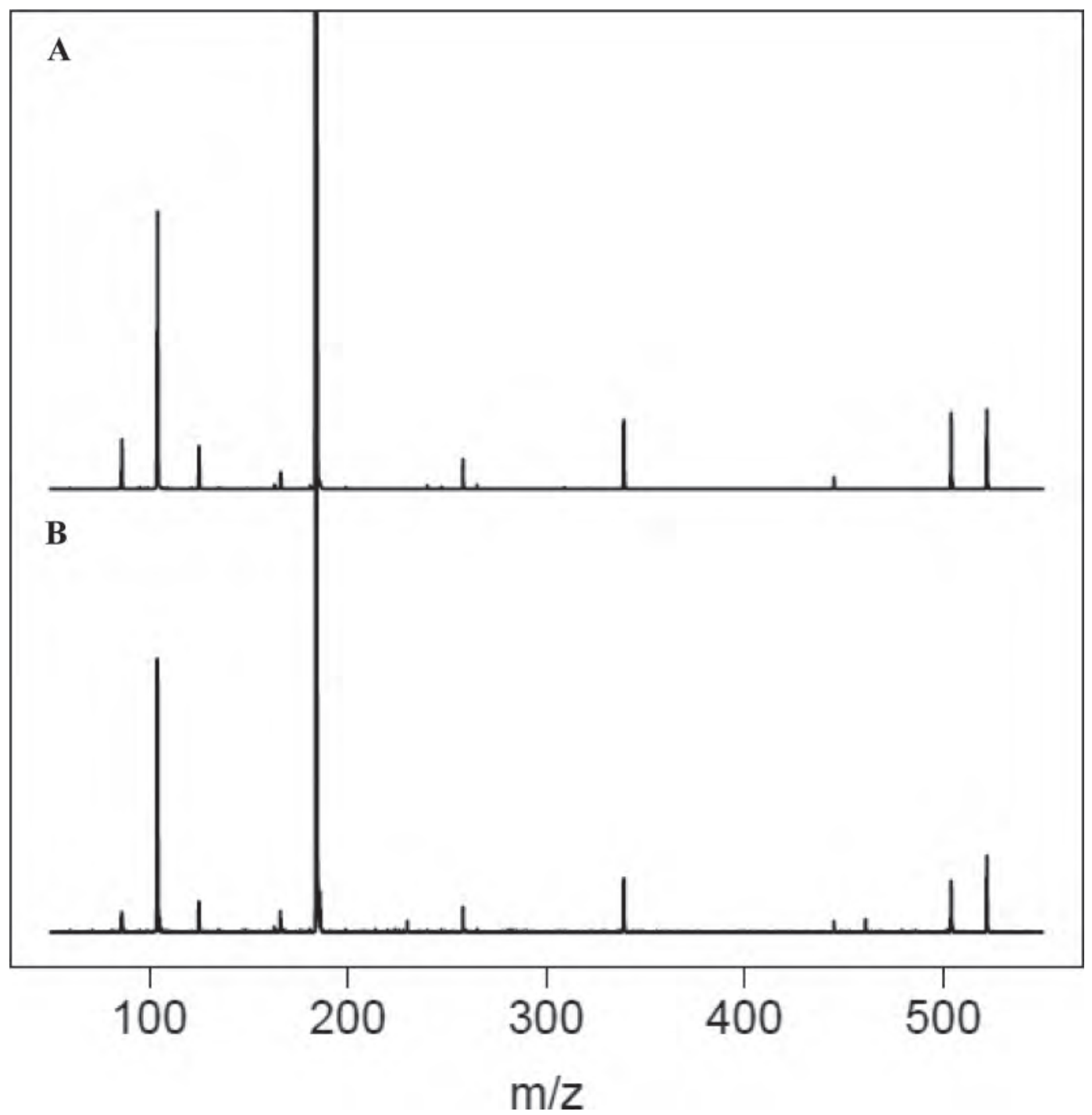

Figure 6. Fragmentation spectra of mass-to-charge ratio $(\mathrm{m} / \mathrm{z}) 522$ from a solution of commercial 2-oleoyl-3-phosphatidylcholine standard (A) and from plasma samples (B). The fragment at $\mathrm{m} / z 185$ is plotted with $50 \%$ of its true intensity to bring the other signals into scale. 


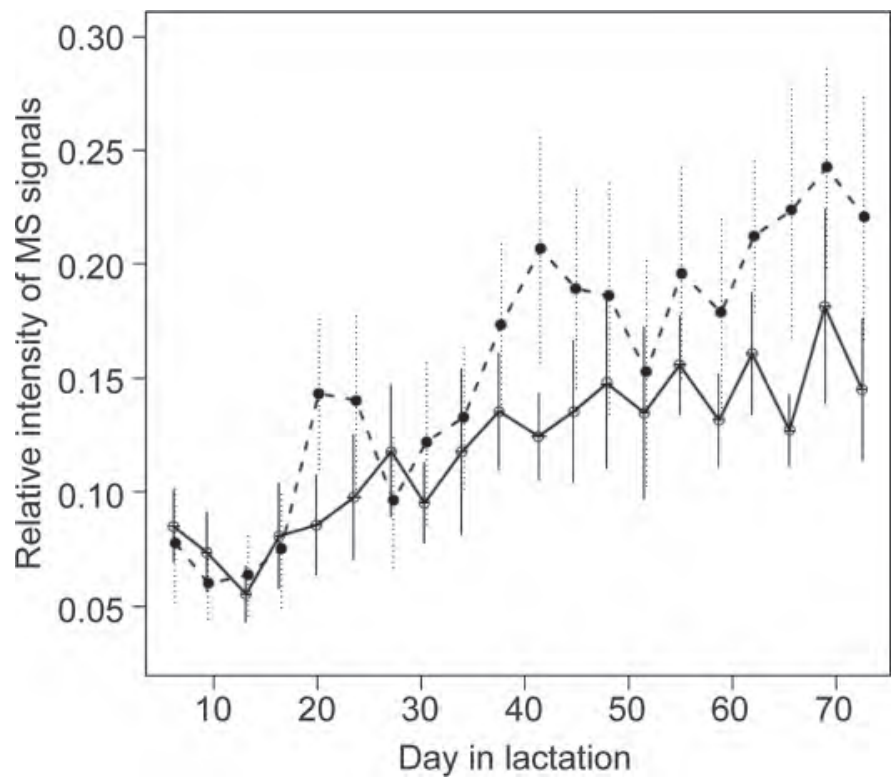

Figure 7. Levels of arachidonyl-phosphatidylcholine (solid line) and linoleyl-phosphatidylcholine (dashed line) in blood plasma during the first months of lactation. MS = mass spectrometry.

PUFA are used for the synthesis of milk fat (Easter et al., 1971), changes observed during the study period in blood phosphatidylcholine (an increase; Figure 7) coincide with the changes observed in milk citrate (a decrease) and are the result of the shift in the balance of preformed and de novo-synthesized FA in milk lipids: in the course of lactation, the proportion of preformed FA derived from blood decreases, and the proportion of de novo-synthesized FA increases (Kay et al., 2005)

The blood-to-milk correlation for the signals of PUFA-related molecules was weak, but this was not surprising considering the pathways of preformed milk FA and lipid synthesis in the mammary gland (Easter et al., 1971; Bauman and Griinari, 2003; Bauman et al., 2011).

Within the study period, the molecular composition of plasma was a result less of lactation-driven changes than of the composition of the milk. Additionally, plasma samples showed a higher degree of individuality, whereas the milk spectra from different animals were more readily comparable. Correlations between plasma and milk mass spectra were calculated. Only animal A showed a mean correlation $(\mathrm{r}=0.2)$ between negative ion spectra from milk and plasma. All other comparisons gave means of $-0.1<\mathrm{r}<0.1$. Therefore, the global metabolome, as a sum of individual compounds of milk and plasma, were not correlated. Nevertheless, a few individual compounds showed at least moderate correlations: most important, in the positive ionization mode $m / z 114(\mathrm{r}=0.47)$, identified as creatinine, and in the negative ionization mode $m / z 184(\mathrm{r}=0.40), 201$ $(\mathrm{r}=0.53)$, and $798(\mathrm{r}=0.40)$. Fragmentation analysis indicated the presence of a carboxyl group in $m / z 184$ and a phosphate group in $m / z 201$, yet both compounds eluted late from the $\mathrm{C} 18$ column, implying the presence of hydrophobic moieties. It was surprising that $\mathrm{m} / z 301$ $(\mathrm{r}=-0.41), 391(\mathrm{r}=-0.43), 554$ to $557(\mathrm{r}=-0.5)$, and $616(\mathrm{r}=-0.47)$ were negatively correlated between blood and milk. Whether these negative correlations could be of biological importance or are false positive hits is yet unclear.

\section{CONCLUSIONS}

A study following changes in low molecular weight metabolites in milk and blood during the first months of lactation was performed. In the milk of different cows, common evolutions in time resolved. Citrate and lactose were found to contribute the most in apparent evolution over time, probably because of their abundance. Statistically, however, the most significant changes were attributed to phosphorylated saccharides, the levels of which decreased during the first 40 DIM. Little correlation was found between blood and milk metabolites; unsupervised classification of blood metabolomes was found to be based on the classes of individual cows. However, in blood a common increase was found in PUFA esters incorporated into phosphatidylcholine. This work demonstrates how minor metabolites may be significantly altered over the course of lactation and that a global metabolomic approach is a promising tool for finding such metabolites.

\section{ACKNOWLEDGMENTS}

This research was supported by grants from the Estonian Science Foundation (Tallinn; grants 7494 and 7856) and the Estonian Ministry of Education and Research (Tartu; SF 0170165s08). The publication of this study is supported by the Graduate School in Biomedicine and Biotechnology (Tartu; project no. 1.2.0401.09-0073).

\section{REFERENCES}

AOAC Int. 2005. Animal feed. Pages 1-72 in Official Methods of Analysis of AOAC International. 18th ed. W. Horwitz and G. W. Latimer, ed. AOAC Int., Gaithersburg, MD.

Bauman, D. E., and J. M. Griinari. 2003. Nutritional regulation of milk fat synthesis. Annu. Rev. Nutr. 23:203-227.

Bauman, D. E., K. J. Harvatine, and A. L. Lock. 2011. Nutrigenomics, rumen-derived bioactive fatty acids, and the regulation of milk fat synthesis. Annu. Rev. Nutr. 31:299-319.

Bitman, J., and D. L. Wood. 1990. Changes in milk fat phospholipids during lactation. J. Dairy Sci. 73:1208-1216.

Bossaert, P., J. L. M. R. Leroy, S. De Vliegher, and G. Opsomer. 2008. Interrelations between glucose-induced insulin response, metabolic 
indicators, and time of first ovulation in high-yielding dairy cows. J. Dairy Sci. 91:3363-3371.

Boudonck, K., M. Mitchell, J. Wulff, and J. Ryals. 2009. Characterization of the biochemical variability of bovine milk using metabolomics. Metabolomics 5:375-386.

Chadeau-Hyam, M., T. M. D. Ebbels, I. J. Brown, Q. Chan, J. Stamler, C. C. Huang, M. L. Daviglus, H. Ueshima, L. Zhao, E. Holmes, J. K. Nicholson, P. Elliott, and M. De Iorio. 2010. Metabolic profiling and the metabolome-wide association study: Significance level for biomarker identification. J. Proteome Res. 9:4620-4627.

Contreras, G. A., N. J. O'Boyle, T. H. Herdt, and L. M. Sordillo. 2010 Lipomobilization in periparturient dairy cows influences the composition of plasma nonesterified fatty acids and leukocyte phospholipid fatty acids. J. Dairy Sci. 93:2508-2516.

DePeters, E. J., J. F. Medrano, and B. A. Reed. 1995. Fatty-acid composition of milk fat from three breeds of dairy cattle. Can. J. Anim. Sci. 75:267-269.

Douglas, G. N., J. Rehage, A. D. Beaulieu, A. O. Bahaa, and J. K. Drackley. 2007. Prepartum nutrition alters fatty acid composition in plasma, adipose tissue, and liver lipids of periparturient dairy cows. J. Dairy Sci. 90:2941-2959.

Easter, D. J., S. Patton, and R. D. McCarthy. 1971. Metabolism of phospholipid in mammary gland: I. The supply of phospholipid for milk synthesis in the rat and goat. Lipids 6:844-849.

Edmonson, A. J., I. J. Lean, L. D. Weaver, T. Farver, and G. Webster. 1989. A body condition scoring chart for Holstein dairy cows. J. Dairy Sci. 72:68-78.

Elgersma, A., G. Ellen, H. van der Horst, H. Boer, P. R. Dekker, and S. Tamminga. 2004. Quick changes in milk fat composition from cows after transition from fresh grass to a silage diet. Anim. Feed Sci. Technol. 117:13-27.

Fox, P. T. 2009. Milk: An overview. Pages 1-44 in Milk Proteins: From Expression to Food. A. Thompson, M. Boland, and H. Singh, ed. Elsevier Inc., Oxford, UK.

Garnsworthy, P. C., L. L. Masson, A. L. Lock, and T. T. Mottram. 2006. Variation of milk citrate with stage of lactation and de novo fatty acid synthesis in dairy cows. J. Dairy Sci. 89:1604-1612.

Grant, R. J., V. F. Colenbrander, and D. R. Mertens. 1990. Milk fat depression in dairy cows: Role of particle size of alfalfa hay. J. Dairy Sci. 73:1823-1833.

Gross, J., H. A. van Dorland, R. M. Bruckmaier, and F. J. Schwarz. 2011. Milk fatty acid profile related to energy balance in dairy cows. J. Dairy Res. 78:479-488.

Guretzky, N. A. J., D. B. Carlson, J. E. Garrett, and J. K. Drackley. 2006. Lipid metabolite profiles and milk production for Holstein and Jersey cows fed rumen-protected choline during the periparturient period. J. Dairy Sci. 89:188-200.

Harzia, H., K. Kilk, I. Jõudu, M. Henno, O. Kärt, and U. Soomets. 2012. Comparison of the metabolic profiles of noncoagulating and coagulating bovine milk. J. Dairy Sci. 95:533-540.

He, M., and L. E. Armentano. 2011. Effect of fatty acid profile in vegetable oils and antioxidant supplementation on dairy cattle performance and milk fat depression. J. Dairy Sci. 94:2481-2491.

Heuer, C., W. M. Van Straalen, Y. H. Schukken, A. Dirkzwager, and J. Noordhuizen. 2000. Prediction of energy balance in a high yielding dairy herd in early lactation: Model development and precision. Livest. Prod. Sci. 65:91-105.

Holtenius, K., S. Agenas, C. Delavaud, and Y. Chilliard. 2003. Effects of feeding intensity during the dry period. 2. Metabolic and hormonal responses. J. Dairy Sci. 86:883-891.

Kay, J. K., W. J. Weber, C. E. Moore, D. E. Bauman, L. B. Hansen, H. Chester-Jones, B. A. Crooker, and L. H. Baumgard. 2005. Effects of week of lactation and genetic selection for milk yield on milk fatty acid composition in Holstein cows. J. Dairy Sci 88:3886-3893

Klein, M. S., M. F. Almstetter, G. Schlamberger, N. Nurnberger, K. Dettmer, P. J. Oefner, H. H. D. Meyer, S. Wiedemann, and W. Gronwald. 2010. Nuclear magnetic resonance and mass spectrometry-based milk metabolomics in dairy cows during early and late lactation. J. Dairy Sci. 93:1539-1550.

Klein, M. S., N. Buttchereit, S. P. Miemczyk, A.-K. Immervoll, C. Louis, S. Wiedemann, W. Junge, G. Thaller, P. J. Oefner, and W. Gronwald. 2012. NMR metabolomic analysis of dairy cows reveals milk glycerophosphocholine to phosphocholine ratio as prognostic biomarker for risk of ketosis. J. Proteome Res. 11:1373-1381.

McGeown, M. G., and F. H. Malpress. 1952. Studies on the synthesis of lactose by the mammary gland. II. The sugar-phosphate esters of milk. Biochem. J. 52:606-611.

Muir, D. D. 2002. Lactose: Properties, production, applications. Pages 1525-1529 in Encyclopedia of Dairy Sciences. Vol. 3. H. Roginski, J. W. Fuquay, and P. F. Fox, ed. Academic Press, London, UK.

Nielsen, N. I., K. L. Ingvartsen, and T. Larsen. 2003. Diurnal variation and the effect of feed restriction on plasma and milk metabolites in TMR-fed dairy cows. J. Vet. Med. A Physiol. Pathol. Clin. Med. 50:88-97.

Nousiainen, J., K. J. Shingfield, and P. Huhtanen. 2004. Evaluation of milk urea nitrogen as a diagnostic of protein feeding. J. Dairy Sci. 87:386-398.

Petzold, C. J., M. D. Leavell, and J. A. Leary. 2004. Screening and identification of acidic carbohydrates in bovine colostrum by using ion/molecule reactions and Fourier transform ion cyclotron resonance mass spectrometry: Specificity toward phosphorylated complexes. Anal. Chem. 76:203-210.

R Development Core Team. 2008. R: A Language and Environment for Statistical Computing. R Foundation for Statistical Computing, Vienna, Austria. Accessed Jun. 12, 2012. http://www.R-project. org.

Rochfort, S. 2005. Metabolomics reviewed: A new "omics" platform technology for systems biology and implications for natural products research. J. Nat. Prod. 68:1813-1820.

Rook, J. A. F., and R. C. Campling. 1965. Effect of stage and number of lactation on the yield and composition of cow's milk. J. Dairy Res. 32:45-55.

Roux, A., D. Lison, C. Junot, and J. F. Heilier. 2011. Applications of liquid chromatography coupled to mass spectrometry-based metabolomics in clinical chemistry and toxicology: A review. Clin. Biochem. 44:119-135.

Sjaunja, L. O., L. Baevre, L. Junkkarinen, J. Pedersen, and J. Setala. 1990. A Nordic proposal for an energy corrected milk (ECM) formula. Pages 156-157 in Proc. Int. Comm. Anim. Recording (ICAR), 27th Session, Paris, France. EAAP Publication No. 50, 1991. Centre for Agricultural Publishing and Documentation $(\mathrm{Pu}-$ doc), Wageningen, the Netherlands.

van den Top, A. M., T. Wensing, M. J. Geelen, G. H. Wentink, A. T. van't Klooster, and A. C. Beynen. 1995. Time trends of plasma lipids and enzymes synthesizing hepatic triacylglycerol during postpartum development of fatty liver in dairy cows. J. Dairy Sci. 78:2208-2220

Waite, R., J. C. D. White, and A. Robertson. 1956. 613. Variations in the chemical composition of milk with particular reference to the solids-not-fat: I. The effect of stage of lactation, season of year and age of cow. J. Dairy Res. 23:65-81.

Zhang, A., H. Sun, P. Wang, Y. Han, and X. Wang. 2012. Recent and potential developments of biofluid analyses in metabolomics. J. Proteomics 75:1079-1088. 